\title{
Cervical Cancer pN1 TNM Finding v8
}

National Cancer Institute

\section{Source}

National Cancer Institute. Cervical Cancer pN1 TNM Finding v8. NCI Thesaurus. Code C139729.

Cervical cancer with regional lymph node metastasis. (from AJCC 8th Ed.) 